\title{
An African Alternative to Western Cosmological Argument Hopeless Reliance on Ontological Argument
}

\section{| Kiatezua Lubanzadio Luyaluka |}

Institut des Sciences

Animiques Kinshasa,

Democratic Republic of Congo

kiatezuall@yahoo.fr

\begin{abstract}
This paper demonstrates that as used in Western philosophy cosmological argument relies on ontological argument to jump to its conclusion about the existence of a Supreme-being-creator. Pointing to the failure of the Western cosmological argument, the paper shows that either creation happens within the creator or outside of him. In the first case, the Supreme-being-creator is not immutable; hence, he is not perfect. In the second case a greater being can be conceived which includes creator and creation. Therefore, the Western cosmological argument hopelessly relies on ontological argument to anticipate a priori that the first cause of its conclusion is God, the greatest possible being and a being of maximum perfection. As an alternative to this debunked cosmological argument, this paper offers the kemetic cosmological argument as a valid demonstration of the existence of a Supreme Being absolutely immutable and who is the greatest possible being. KEYWORDS

Cosmological argument; ontological argument; Kôngo; Bukôngo; monotheism; ancient Egypt.
\end{abstract}

\section{INTRODUCTION}

In natural theology, cosmological argument is one of the most relied approach for the demonstration of the existence of God through logic. The most ancient use of this argument is found in the book X of the work of the Grecian philosopher Plato titled the Law. As used by Western philosophy (Arabic and European) cosmological argument starts from the "the presence of the cosmos back to a creator of the cosmos".

According to R. Koons this argument obeys to the following schema:

1. Everything of type $\mathrm{X}$ has a cause.

2. There is something of type $X$.

3. For some reason (namely, Y), the series of causes of an X must terminate in a first cause.

4. This first cause can be identified with God.

In the history of Western philosophy, one of the critics against cosmological argument came from the German philosopher Emmanuel Kant. He argued in his Critic of pure reason that cosmological argument relies on ontological argument to reach its conclusion. According to Koons, it is very clear that Kant believed that cosmological argument depends on ontological argument. However, this author adds that "it is much less clear why Kant believed this dependence to hold".

In this paper we intend to reenact the contention that, as used in Western philosophy, cosmological argument fails to prove that the being identified with God is the Supremebeing-creator of the monotheism of its religions (Christianity, Judaism, and Islam). Thus, to infer such a conclusion, this argument fills an undemonstrated gap by relying on ontological argument. 
To prove the failure of Western cosmological argument (WCA), we will demonstrate that the existence of a supreme-being-creator is a logical impossibility. Thus, to conclude that the God whose existence is demonstrated by logical inference is the Supreme-being-creator, the WCA relies on ontological argument, i.e., on a priori argument.

This outcome will lead us to assert that the WCA is an unfinished attempt of the demonstration of the existence of the Supreme Being. To sustain this point, we will show that there is a cosmological argument which carried to its logical conclusion enables one to prove, without relying on ontological argument, that the Supreme Being is absolutely immutable and is the greatest possible being. The monotheism thus demonstrated through the kemetic cosmological argument (KCA) is the notion of theism of the ancient civilizations of Egypt which has been continued in African traditional religion, especially in Kôngo religion, Bukôngo (Thompson, 1996).

\section{On the Ontological Argument}

An ontological argument is an a priori demonstration of the existence of God. This argument affirms that due to an assumed nature of the Supreme Being, he cannot not exist. There are several versions of which the "the most famous was first developed by St. Anselm, the eleventh century Archbishop of Canterbury".(Koons, 2002). Anselm's ontological argument as stated in his book titled Proslogion affirms that being the greatest possible being, God cannot not exist.

Anselm's ontological argument can be understood in this way: the greatest possible being cannot exist in understanding only; because, if it were so, one can imagine in his mind a being greater than the greatest possible being, which necessarily entails a contradiction. Therefore, the greatest possible being must exist in reality.

Another important ontological argument was stated by A. Plantinga. It affirms that God is a maximally excellent being, i.e., "one that is omniscient, omnipotent, and morally perfect in every possible world".

As we said above, our purpose in this paper is to demonstrate that the various cosmological arguments offered by Western philosophy are unable to demonstrate the existence of the God defined as the Supreme-being-creator. Therefore, ontological arguments help the WCA to jump to the conclusion of the existence of this greatest and maximally perfect being.

\section{The Failure of The Wca}

As carried in Western philosophy, cosmological argument reaches the conclusion of the existence of a first cause; this one is identified to the creator of this temporal universe. Since, within the framework of the unicity of God sustained by its theism, this creator is claimed to be the Supreme Being, to appraise this claim the following question has been asked: what is the locus of his creation?

There are only two possibilities to answer this question:

1 Creation really occurs within the creator.

2 Creation really occurs outside of the creator.

\section{Creation Really Occurs within the Creator}

If creation really occurs within the creator, at the moment of creation, its modus operandi implies that something in the divine Mind goes from potentiality to actuality. In other words, God undergoes an inner change. This change leads to the conclusion that God is mutable. However, a mutable God cannot be a maximally excellent being (of Plantinga's ontological 
argument) due to the possible existence of potentialities that are not yet actualized, as induced by his mutability.

Moreover, recent advances in cosmology have proven that our universe is temporal. The big-bang theory implies that the universe is constantly expanding; this expansion leads to the conclusion that there is a starting point of the expansion which is the beginning of the universe. A. Z. Jones \& D. Robbins put it this way:

It soon became evident that an expanding universe was once very much smaller so small, in fact, that it was compressed down to a single point (or, at least, a very small area). The theory that the universe started from such a primordial point and has expanded ever since is known as the big bang theory.

Though, alternative views exist which disprove the beginning of the universe from a "single point", the big-bang theory is so far the one explanation of the beginning of this universe sustained by modern Western cosmology.

On the other hand, the second law of thermodynamics leads to the conclusion that the universe is running inexorably toward an end, a point of maximum entropy. Now, these two conclusions of modern Western physics point to the mutability of the creator if creation really occurs within him.

Even from the point of view of the Bible, the universe is described as running toward its end. The Scriptures affirm this end in the following manner:

The day of the Lord will come as a thief in the night; in which the heavens shall pass away with a great noise, and the elements shall melt with fervent heat, the earth also and the works that are therein shall be burned up.

This sustains the fact that the creator will unavoidably sustains another inner change due to the inexorable end of his created order. This changing creator cannot be the maximally perfect being that the ontological argument of Plantinga sustains. Therefore, by asserting that its ultimate cause is the Supreme-Being-creator cosmological argument jumps to a conclusion that it cannot sustain through logical reasoning. This it does because in Western theism God is supposed to be only one, i.e., the one defined by ontological argument; therefore, any demonstration by the WCA of the existence of a first cause of this temporal universe must be construed as the demonstration of the God of the ontological argument.

\section{Creation really occurs outside of the creator}

The Bible affirms that "the Lord God formed man of the dust of the ground, and breathed into his nostrils the breath of life; and man became a living soul". Literally this passage seems to sustain that God acted as a potter, giving a form to a chunk of clay and instilling in it a spirit of life. Therefore, creation really occurs outside the creative principle.

If creation really occurs outside of the creator, as it is generally understood, then one can conceive a greater reality including the creator and his creation. According to the ontological argument of Anselm of Canterbury, that greatest reality is the greatest possible being, thus it is the Most-high. However, this induces a contradiction because God is supposed to be the Supreme-being-creator, the greatest possible being is understood in Western theism as the creator.

To put it otherwise, the hypothesis of the existence of creation outside of the creator implies that God, the Supreme-being-creator, is not absolutely infinite; because absolute infinity must necessarily include the creator and his creation. Thus, as we said above, to conclude that the God arrived at through WCA is the Supreme Being, Western philosophy must necessarily rely on its ontological arguments. All this implies that, in reality, the cosmological argument as used in Western philosophy is an unfinished attempted demonstration of the existence of a Supreme Being. 


\section{The Wca an Unfinished Reasoning}

According to logicians, deduction is a form of reasoning where, "it is not possible for the premises all to be true while the conclusion is false". This definition implies that, drawn from true premises, as a good cosmological argument usually is, its attempt must always yield a true conclusion. This should be the case because the conclusion of a deduction is in reality included in the premises. However, we have seen in the above section that the conclusion which is reached about God as being the Supreme-being-creator is not logically valid.

This outcome reveals that, though it is a valid reasoning, as implied by its deductive approach, the WCA is however an unfinished reasoning as far as its claim to demonstrate the existence of a Supreme-being-creator is concerned. This unfinished argument jumps to conclusion by using the ontological argument as stated by Anselm of Canterbury and Plantinga. Thus, the WCA obeys to the following schema:

1. The cosmological argument demonstrates the existence of an ultimate cause.

2. This cause should be identified to God, the creator.

3. According to ontological argument, God cannot not exist.

4. Since God exists, because his existence is demonstrated by the cosmological argument, then this God must be the one defined in ontological argument, all the more as there is only one God within the framework of Western monotheism.

5. Therefore, the God demonstrated by the WCA is the greatest possible being, a being of maximum perfection; he is the Supreme-being-creator.

It is obvious, as seen in the mutability of the creator, that without ontological argument, the WCA cannot prove that the God inferred through its logic is the absolutely infinite and perfect being taught by Western theology and defined by ontological argument.

The most that the WCA does is to demonstrate that there is an ultimate cause of this temporal universe. However, as pointed by an author, "even if some argument for the first step should be entirely successful, there remains the difficult task of establishing that the first cause or self - existent being is God". Therefore, to jump to the conclusion that this ultimate cause is the Supreme-being-creator defined by Western monotheism is to fill a gap with an a priori assertion.

\section{On the Validity of Western Monotheism}

This outcome shows that the failure of the WCA can be assimilated to the failure of the very concept of monotheism sustained by Europeans and Arabic philosophers and theologians as the existence of a Supreme-being-creator.

We have seen above that the very notion of creation implies the existence of a reality greater than the creator and the mutability of this one; thus, the creator cannot be the God claimed by ontological argument.

Therefore, the failure of the WCA is in reality inherent to the failure of the notion of God as a Supreme-being-creator. The impossibility of this concept has been clamored even by Western thinkers who conclude that "God turns out to be a logically impossible being".

This state of things leads many thinkers to approach Western theism from non-realists' perspective for two reasons. Firstly, according to P. Vardy, "The arguments for the existence of God favored by natural theology do not succeed", the reason offered for this assertion is that they are based on assumptions that are not convincing to non-believers. Secondly, the epistemology which depends on revelation "does not succeed in establishing truth"; the reason for this second argument is that this epistemology depends on assumptions that are not universal. 
Since at the core of the failure of the WCA lie assumptions about the nature God that are not universal, the question is then: how can one reconcile the notion of a creator and the existence of the greatest possible being who is a being of maximal perfection? Our answer to this query is the kemetic cosmological argument (KCA), an argument on the existence of a Most-high being which is in line with the notion of theism of the ancient civilization of Egypt and which is also the original form of African traditional religion (ATR), especially Bukôngo.

\section{An Exposition of The Kca}

We have seen above that the failure of the WCA is the failure of the notion of theism it tries to demonstrate as well as the unfinished nature of its reasoning. Our purpose in this section is to propose an alternative to the WCA. This new argument will be in line with the notion of theism developed in the Egyptian theology of Memphis; hence we will label it kemetic.

As an African alternative to the WCA, the KCA is in line with the theism which characterizes Bukôngo. Now, the various trends of African traditional religion, have been demonstrated to be the devolutions of the original religion that characterized the ancient civilization of Egypt, and which is continued in Bukôngo. Therefore, the KCA defines the original nature of the theism of ATR.

Moreover, since the Western notion of a supreme-being-creator has been proven to be a logical impossibility, the KCA will aim a singular kind of theism; hierarchical monotheism implies the existence of a Supreme-being different from the creator who is his demiurge.

For the purpose of this article, the KCA can be in summary introduced in the following manner:

- This temporal universe is made of individualities; thus it is individual. Its particular nature is a contingency.

- A necessary cause exist which includes this universe and explains its contingency. Being the cause of an individual universe, this cause is individual.

- The individual nature of this necessary cause implies the existence of other ones endowed at least with potential causation.

- The possession of individualities by these necessary causes requires a causal principle.

- Thus, an absolutely necessary cause exists which includes all the above inferred relative necessary causes and explains their contingency.

- Since any conceived universe is included in its creator, the all-including absolutely necessary being is the greatest possible being.

- Moreover, the Supreme-being is absolutely non-contingent and indivisible, because any lesser nature will invite the existence of a cause higher than the greatest possible being, which is impossible.

- Being the ultimate cause, this greatest possible being is the Supreme Being. Thus, the Supreme Being is absolutely infinite, infinite in the nature of his individuality and in the quantity of individualities he includes, any lesser essence will entail contingency. Being without any contingency the Supreme Being is absolutely unchanging.

- The indivisiblity of the Supreme-being implies that, as his manifestations the creative causes express his completeness that we call the Word. Thus, the Most-high, the ceator and the Word are inseparable in their existence, subastance and activily. It follows from this trinity tha the creator can only act through the impulse of the Word.

- As for the existence of this temporal universe, four possible alternatives exist for its locus in relation to an absolutely unchanging Supreme Being and his absolutely infinite and unchanging realm: 
- This temporal universe doesn't exist. This alternative is not valid because the existence of this temporal universe is assumed as the starting point of the KCA.

- This temporal universe exist within the eternal realm, the realm of the Supreme Being. This alternative is not valid because the Most-high is absolutely without any contingence and absolutely immutable.

o This temporal universe exists outside the eternal realm. This is an impossible alternative because the eternal realm is absolutely infinite, it includes all reality.

- This temporal universe exists along the eternal realm. This is the only remaining option. However, since the eternal realm includes all reality, it implies that the temporal realm is only a perspective of the eternal one. This perspective is an illusorily limited perception of the eternal reality.

\section{An illusory temporal universe as an African notion}

This perception of the temporal universe as a mere appearance is in conformity with the African worldview. It has been sustained by Plato in his theory of archetypes. Considering the materialistic nature of Grecian worldview, it can be assumed that Plato took this conception from Egypt where he studied. Moreover, the same notion of this temporal universe is affirmed of some Nigerians by F. Omotosho in this manner: "to the Yorubas of southern Nigeria our world like Plato's empirical world is a mere appearance". The same perception is found among the Bantu ethnics of the Democratic Republic of Congo as characterizing the concept of human body as a mere appearance compared to the soul.

It must be clarified that the illusory nature of the temporal universe is restricted to the limitation that the perspective tries to affix to the eternal realm, but not to the good that appears in this limited perception of reality. This should be the case because, being the sum total or reality, the Supreme Being is the substance of that good.

\section{The KCA and the African Notion of Theism}

The KCA has evidenced the existence of a Most-high God different from the creator; it is evident from his very nature that this Supreme Being is transcendent. Now, first of all, it must be noticed that the existence of the Most-high God in Egypt is affirmed by many Egyptologists, by the Pyramid text of Unas (Text No. 171) and implicitly by the Egyptian book of the dead which speaks of the creator Ra as a child of Nut (the heaven), thus inducing the existence on a causal order higher than the creator. .

According to Rawlinson (1886), the Most-high in Egypt was neither named nor represented. This is due to his transcendent nature. This transcendence of the Egyptian Supreme Being is seen in the fact that prayers were never addressed directly to him, but to lower divinities the highest to who is Ra.

This transcendence of the Most-high God is seen also in Bukôngo where, according to a famous prayer offered by the Kôngo prophet Simon Kmbangu, as quoted by Bandzouzi, Nzâmbi Ampûngu Tulêndo (the Supreme Being) is different from the creator (Mbûmba Lowa). Speaking of this transcendence van Wing affirms "Nzâmbi is unique, apart from everything else, invisible and yet living, acting in sovereignty, independent, elusive and inaccessible, yet leading men and things closely and with absolute efficiency".

This transcendent nature of the Nzâmbi Ampûngu Tulêndo is also affirmed by Bittremieux "N'zâmbi cannot have equal, He is not even (...) the "primus inter pares" or the term of an animist evolution, a polytheist one, or another, but the One, the Inaccessible, the Great Chief, who from his empyrean dominates everything"].

The existence of two creative principles (the Creator and the Word) in consonance with the transcendence of the Most-high is confirmed of ancient Egypt by the theology of 
Memphis. Speaking of the creator (Atom) and of the Word (Ptah) in Memphite theology James affirms, "Atum, i.e., Atom, having absorbed the thought and creative power of Ptah, then proceeds with the work of Creation".

Table 1. Comparative table of hierarchies of divinities

\begin{tabular}{lll}
\hline KCA & Egypt (Memphis) & Bukôngo \\
\hline Most-high & Unnamed God & Nzâmbi Ampûngu Tulêndo \\
Creator & Atom & Mbûmba Lowa (the solar creator) \\
Word & Ptah & Npina Nza (the God governor) \\
\hline
\end{tabular}

The table 1 shows the total correspondence that exists between the theism of ancient Egypt, and Bukôngo. The divinities of Bukôngo are known thanks to a prayer of the Kôngo prophet Simon Kimbangu.

\section{On the Validity of the KCA}

All that precedes shows that, contrary to the WCA, the KCA demonstrates logically the existence of Supreme Being who is absolutely infinite and maximally perfect without resorting to ontological argument. The only remaining question is that of the validity and veracity of the KCA.

The KCA is a deduction from a true premises (the existence of individualities and the law of causalities); therefore, according to the very definition of deduction, the KCA is a valid reasoning because in a deduction "it is not possible for the premises all to be true while the conclusion is false".

On the cosmological plan, the KCA implies the existence of two spaces-times: an absolute space-time which includes the relative spaces-times (the earth, or our observable cosmos, and the different heavens). Creation occurs in the temporal plane; but the creator, impelled by the Word, moves back to the necessary plane. This move of the creator impels the isotropic acceleration of the absolute space-time to nothingness and naturally explains the dynamics of the universe (gravitation, translation, rotation and the equilibrium of the bodies) at the astronomic and subatomic levels, a holistic "theory of everything".

Let $\mathrm{A}$ and $\mathrm{B}$ be two points of the universe situated at the intersection of the absolute spacetime and a relative one; the distance $\mathrm{AB}$ measured in both spaces-times are respectively: $r_{1}$ and $r$. We suppose the acceleration of the relative space-time to be negligible in this calculation.

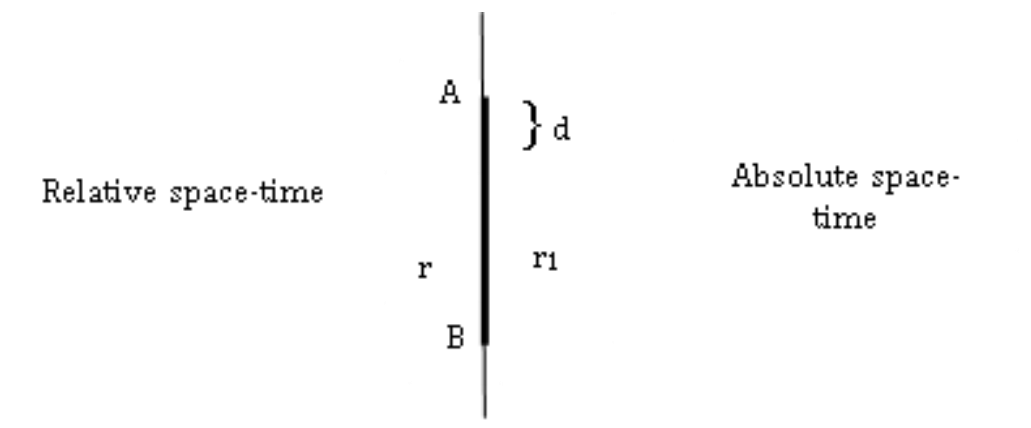

At the instant $t_{0}$, an observers placed at point $\mathrm{B}$ sees the situation according to the equation: $r_{1}=r(1)$. As time elapses, $r_{1}$ dwindles as to lose the distance $d$. Thus we have $r_{1}=r-d$. Now, $d$ can be written as a factor of $r$ to have $r_{1}=r-r k(2)$. With $0 \leq k \leq 1$. The equation of the uniform and rectilinear acceleration of the dwindling of $k$ is $k=k_{0}+v_{0} t+\frac{1}{2} g t^{2}$ (3). With the initial magnitude and velocity both null, the equation (3) yields $k=\frac{1}{2} g t^{2}(4)$. By substituting this value of $k$ in (2) we get $r_{1}=r\left(1-\frac{1}{2} g t^{2}\right)(5)$. A double 
derivation of the equation (5) yields the acceleration of $r_{1}$ calculated according to the time elapsed in the relative space-time: $a=-r g(6)$.

What is dwindling under the acceleration of the absolute space-time toward nothingness is not the isolated segment $r_{1}$ but the volume, or the portion of the absolute space-time that contains it. Thus, we must write $r_{1}$ according to this reality. Let $v_{1}$ be a prism having $r_{1}$ as the sides of its square base. In conformity to the equation (1) we have $v_{1}=h r^{2}$ (7). By writing $h$ as a factor of $r$, we get $v_{1}=q \cdot r^{3}(8)$. From (8) we get $r=\frac{v_{1}}{q r^{2}}(9)$. The exact height of the prism has no incidence of the position of A; thus the ratio $\frac{v_{1}}{q}$ can be taken as a constant $\mathrm{c}$ to get $r=\frac{c}{r^{2}}$ (10). By replacing (10) in (6) one gets $a=-\frac{c g}{r^{2}}(11)$. With $-c g=G$, we finally get $a=\frac{G}{r^{2}}$ (12). Now by multiplying both sides of the equation (12) by the reciprocal masses of the celestial bodies symbolized by the points A and B one gets: $F=G \frac{M m}{r^{2}}$ that is Newton's law of gravitation easily explained according to KCA. This calculation offers us the mathematical verification of the veracity of the KCA.

\section{CONCLUSION}

In this paper we endeavored to demonstrate that as used in Western theological philosophy (Arabic and European) cosmological argument relies on ontological argument to jump to its conclusion about the existence of a Supreme-being-creator.

For this purpose, have shown that, as the demonstration of the existence of the Supreme Being, the Western cosmological argument is a failure because the act of creation necessarily entails the mutability of the creator or the existence of a being greater than him. Thus, the creator cannot be the Supreme Being, i.e., the greatest possible being and a being of maximum perfection.

Therefore, the Western cosmological argument hopelessly relies on ontological argument to anticipate a priori that the ultimate cause arrived at through its demonstration is the greatest possible being and is a being of maximum perfection. Unfortunately, though being a logical impossibility, this Supreme-being-creator is perceived as the only option of Western theology within the framework of its monotheism.

As an alternative to the debunked Western cosmological argument, we offered the kemetic cosmological argument as a deductive reasoning that demonstrates the existence of a Supreme Being absolutely immutable and who is the greatest possible being. This theism has been shown to be the very notion of a Supreme Being different from the creator sustained in ancient Egypt and in African traditional religion, especially Bukôngo.

The validity of the new cosmological argument has been inferred thanks to its deductive nature and its simpler explanation of the dynamics of the universe at the astronomic and subatomic levels, a holistic "theory of everything".

\section{REFERENCES}

Bandzouzi, Alphonse. (2002). Le Kimbanguisme [the Kimbanguism]. Paris: Eki.

Bittremieux, Léo. (1936). La Société secrète des Bakhimba au Mayombe [The Secret society of the Bakhimba in Mayombe]. Bruxelles: Librairie Falk fils. 
Diop, Cheikh. A. (1972). Antériorité des civilisations nègres [Anteriority of Black civilizations]. Abidjan, Côte d'Ivoire: Présence africaine.

Gbadamosi, Oluwatoyin A. (2015). Natural theology and modern science: an exposition on emerging scientific proofs for god's existence in christianity", in Ilorin Journal of Religious Studies, 5 no 2, pp. 23-36.

James, G. G. M. (2009). Stolen legacy: Greek philosophy is stolen Egyptian philosophy. Africology: In The Journal of Pan African Studies http://www.jpanafrican.org/ebooks.htm.

Jones, A. Z. \& Robbins, D. (2010). String theory for dummies, Hoboken, N.J., USA: Wiley Publishing, Inc.

Koons, Robert. C. (2002). Western Theism. Retrieved from http://www.leaderu.com/conversations,

Ladyman, James. (2002). Understanding philosophy of science. London, England: Routledge.

Luyaluka, Kiatezua. L. (2017). African Indigenous Religion and its Ancient Model Reflections of Kôngo Hierarchical Monotheism. The Journal of Black Studies, 48, no 2, pp. 165-185.

Luyaluka, Kiatezua. L. (2017). The Elucidation of Africanness in Christianity through Hierarchical monotheism and its redefinition of Black theology. Black theology an international journal, 15, no.3, pp. 257-278.

Luyaluka, Kiatezua. L. (2017). The Solar Cosmological Interpretation of the Egyptian Nut, Shu, Geb. Scene in Saudi Journal of Humanities and Social Sciences 2. No 8, pp. 669676.

Luyaluka. Kiatezua. L. (2014). Religion and Science Conversion Possibility: Towards the Formulation of a Systematic Theodicy of the African Indigenous Religion and its Reinterpretation of Empirical Cosmology. Journal of Pan African Studies 7. No 7, pp. 108-39.

Meister, Chad. (2009). Introducing philosophy of religion. London, UK: Routledge.

Omotosho, Felicia. A (2014). Critique of the question of African philosophy. IOSR Journal of humanities and social sciences, 19. No 7, pp. 61-66.

Rawlinson, G. (1886). Ancient Egypt. Retrieved from http://www.gutenberg.org.

Rowe, W. L. (2010). Cosmological argument. A Companion to philosophy of religion 2nd edition. Eds. C. Talaferro, P; Drapper \& P. Quinn. Oxford, UK: Blackwell Publishing Ltd, pp. 368-374.

Sayce, A. H. (1903). The Religions of ancient Egypt and Babylonia, Edinburgh, UK: T. \& T. Clark.

Tempels, P. (1945). La Philosophie bantoue [Bantu philosophy]. Elisabethville : Lovania.

Thompson, Berth. \& Jackson, Wayne (1996). The Case for the existence of God. Montgomery: Apologetic press.

Van den Dungen, Win. (2016). The Memphis theology. Retrieved from http://www.maat.sofiatopia.org/memphis.htm.

Van Wing, Joseph. (1956). Etudes Bakôngo [Studies about the Bakongo]. 2nd ed. Brussels Belgium : Librarie Falk fils.

Vardy, Peter (2005). Philosophy of religion. The Routledge companion to religious studies Ed. J. R. Hinnells, London, UK: Routledge, pp. 80-97. 